International Journal of Educational and Psychological Studies - Vol. 3, No. 3, 2018, pp. 704 - 719

\title{
بناء برنامج تدريبي مقترح لتنمية الكفايات التعليمية الأدائية لمعلمات التعليم قبل المدرسة أثناء الخدمة بولاية الجزيرة - السودان
}

\author{
د. خالاد محجوب عبد الله محمود \\ أستاذ المناهج وطرق التدريس المساعد - قسم التربية- كلية التربية الحصاحيصا - جامعة الجزيرة \\ khalid.mahgoub565@gmail.com
}

الملخص:

هدف البحث إلي بناء برنامج تدريبي (مقترح) لتتمية الكفايات التعليمية الأدائية لمعلمات التعليم قبل المدرسة أثناء الخدمة

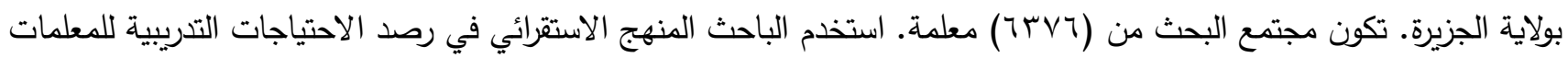
والمنهج الوصفي في وصف البرنامج التدريبي • تم بناء البرنامج التدريبي في الخطوات التالية :

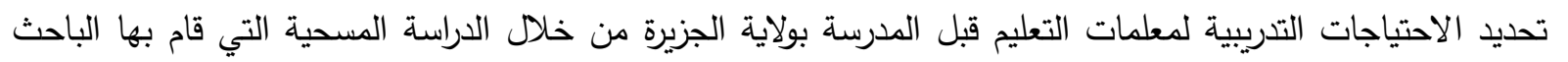
بمشاركة التوجيه الفني وإدارة التعليم قبل المدرسة بمحليات ولاية الجزيرة .

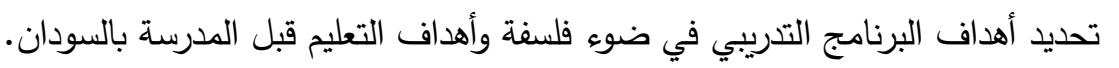
ا اختيار المحتوي والأنشطة التدريبية التي تحقق تتمية الكفايات التعليمية الأدائية للمتدربات. اختيار طرائق وأساليب تتفيذ وتقويم البرنامج والوسائل والتقنيات التدريبية المساعدة في تيسير التدريب.

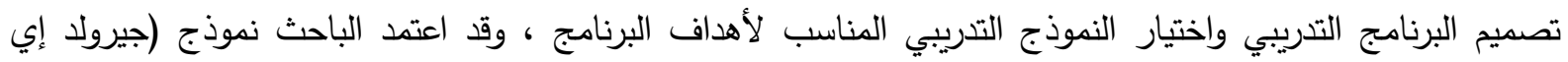

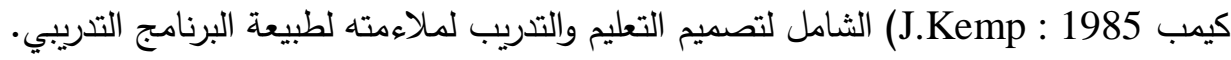
الإعداد لتنفيذ البرنامج، حيث تم تحديد متطلبات تتفيذ البرنامج البشرية والمادية ووضع خطة للتفيذ تضمنت الجدول

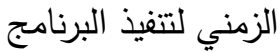

$$
\begin{aligned}
& \text { تتفيذ البرنامج التدريبي وفق الخطة المرسومة. } \\
& \text { تقويم البرنامج التدريبي لمعرفة ددي تحقق أهدافه. } \\
& \text { قدم الباحث في نهاية البحث عدة توصيات ومقترحات لبحوث مستقبلية. } \\
& \text { الكلمات المفتاحية : برنامج تدريبي لمعلمات التعليم قبل المدرسة }
\end{aligned}
$$

\section{(c) 8}

المقدمة :

تعتبر مرحلة التعليم قبل المدرسة اللبنة الأولي في بناء النظام التعليمي لأي بلد من بلدان العالم ، لذا أولتها دول العالم

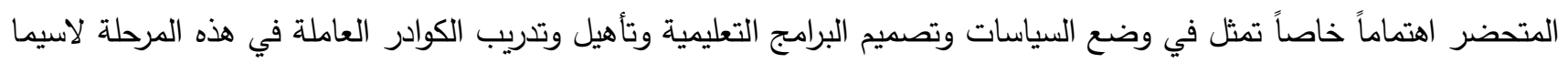
المعلمات اللائي يقع عليهن عبء ترجمة السياسات التعليمية إلي واقع من خلال تتفيذ المنهج المقرر، وتهيئة البيئة التعليمية لاستيعاب الأنشطة التعليمية وتلبية حاجات الأطفال بتوفير الوسائل التعليمية والأجهزة والأدوات والألعاب اللازمة لتعليم الأطفال. 
إن وجود معلمة الروضة المؤهلة بات أحد متطلبات قيام روضة الأطفال، ( فلا تستطيع الروضة المزوّدة بأحدث وسائل التعليم، وأرقي الإمكانات أن تحقق أهدافها بدون معلمة متخصصة ومؤهلة تأهيلاً علمياً في جميع المجالات المهات المهنية والأكاديمية والثقافية، وبدون أن يواكب ذلك برامج الإعداد أثناء الخدمة بشكل يضمن أن تستمر معلمات هذه المرحلة في الاطلاع علي هلي

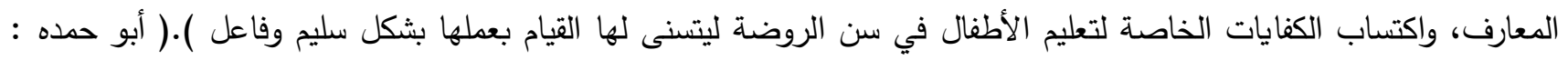

شهد التعليم قبل المدرسة بالسودان عامة وولاية الجزيرة بصفة خاصة توسعاً ملحوظاً في السنوات الأخيرة ، حيث تضاعفت أعداد الأطفال المنتسبين لرياض الأطفال، مما استلزم فتح العديد من الرياض لاستيعاب هؤلاء الأطفال فظهرت الحاجة الماسة لأعداد كبيرة من المعلمات للعمل برياض الأطفال. حيث تم استيعاب بعضهن في وظائف حكومية والبعض الآخر ظل الل يعمل كمتعاونات، واستوعبت رياض الأطفال الخاصة أعداداً غير قليلة منهن .هذه الفترة عرفت بمرحلة الانتشار لتلبية الطلب المتزايد علي

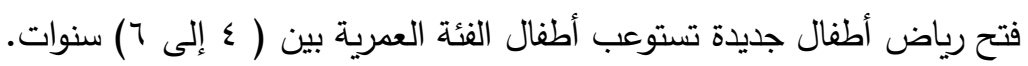
يأتي هذا البحث في محاولة لتوظيف التدريب أثناء الخدمة في تتمية الكفايات التعليمية الأدائية لمعلمات التعليم قبل المدرسة بولاية الجزيرة حيث يقوم ببناء برنامج تدريبي لمعلمات التعليم قبل المدرسة من خلال استقراء الواقع التدريبي الماثل الآن وتحديد

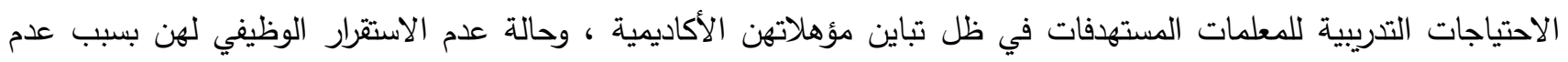

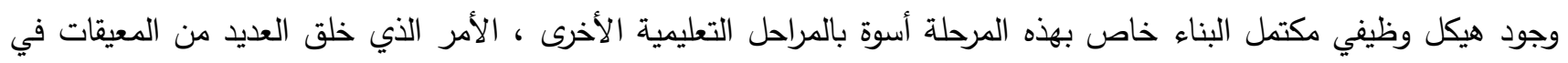
سبيل تطوير التعليم قبل المدرسة بولاية الجزيرة والتي تأتي في مقدمتها ضعف الكفاهي لكايات التعليمية الأدائية للمعلمات.

مشكلة البحث:

ترتب علي الانتشار الكثيف لرياض الأطفال دخول أعداد كبيرة من المعلمات غير المؤهلات للعمل بالتعليم قبل المدرسة

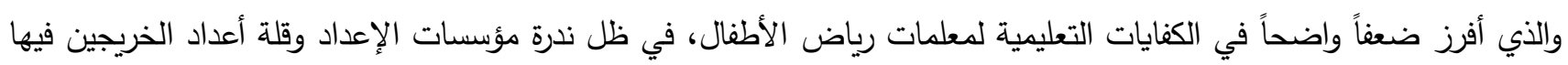
وعدم وجود برامج للتدريب أثناء الخدمة لتتمية الكفايات التعليمية للمعلمات، لذا فإن مشكلة البحث تمثلت في كيفية بناء برنامج تدريبي لتتمية الكفايات التعليمية الأدائية لمعلمات التعليم قبل المدرسة أثناء الخدمة، يلبي احتياجاتهن التدريبية ويستوعب التباين في لتئي مؤهلاتهن في ظل شح الإمكانات المادية.

أهداف البحث:

يهذف هذا البحث إلي بناء برنامج تدريبي ( مقترح ) لتتمية الكفايات التعليمية الأدائية لمعلمات رياض الأطفال أثناء الخدمة بولاية الجزيرة بالسودان.

تتمثل أهمية البحث في الآتي :

• يتتاول أهم المراحل التعليمية من حياة الفرد وهي مرحلة التعليم قبل المدرسة، وأهم أركان هذه المرحلة وهي المعلمة التي

تقوم عليها العملية التعليمية. • يقوم البرنامج علي الكفايات التعليمية وهي أحدث أساليب تدريب المعلمين. • يراعي البرنامج التباين في مؤهلات المعلمات الأكاديمية وخبراتهن العملية.

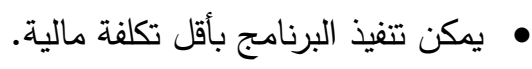

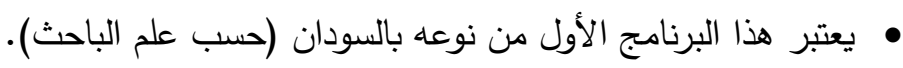
• يعتبر هذا البرنامج مرشداً للباحثين والمهتمين بأمر تدريب المعلمين أثناء الخدمة لا سيما معلمات التعليم قبل المدرسة. 
منهج البحث وأدواته:

استخدم الباحث المنهج الوصفي الذي يقوم بتحليل الظاهرة موضوع البحث وتفسيرها، والمنهج الاستقرائي في ملاحظة أداء

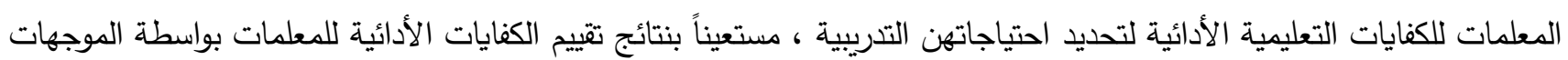
الفنيات بالمحليات اللائي اتفنن علي ضعف مستوي الكفايات الأدائية للمعلمات. وهذه النتيجة تتسجم مع ما ورد في مشكلة البحث.

\section{مجتمع وعينة البحث:}

تكون مجتمع البحث من جميع معلمات التعليم قبل المدرسة بولاية الجزيرة البالغ عددهن ( TrVT ) معلمة (إدارة الإحصاء

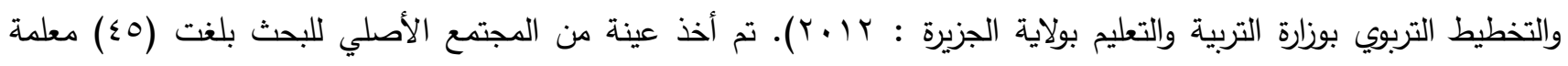
يعملن برياض الأطفال بمحلية المناقل .

حدود البحث:

يُحد هذا البحث بالحدود التالية :

الحدود الموضوعية : الكفايات التعليمية الأدائية لمعلمات التعليم قبل المدرسة (رياض الألئل الطفال).

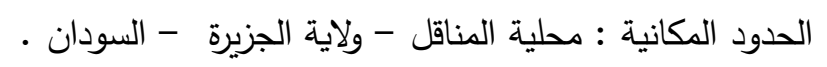

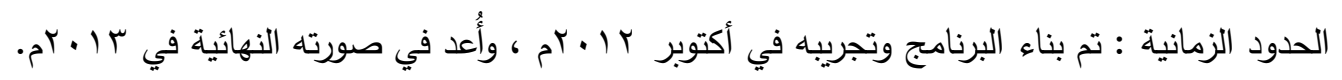

\section{مصطلحات البحث: \\ البرنامج التدرببي:}

عرّفه الطعاني (V • . ץ: ص ع ( ) بأنه الجهود المنظمة والمخطط لها لتزويد المتدربين بمهارات ومعارف وخبرات متجددة تستهدف إحداث تغيرات إيجابية مستمرة في خبراتهم واتجاهاتهم وسلوكهم من أجل تطوير كفاية أدائهم • ويعرّفه الباحث إجرائياً بأنه مجموعة من الأنشطة المخططة المنظمة والتي تستهدف إكساب المتدربات معارف وخبرات ترفع من كفاياتهم الأدائية ، وتقدم في فترة زمنية محددة.

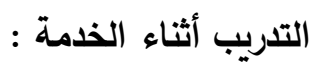

عملية منظمة تتم من خلال مجموعة استراتيجيات معلوماتية وفق معايير محددة للأداء المرغوب فيه وتتضمن بناءً معرفياً

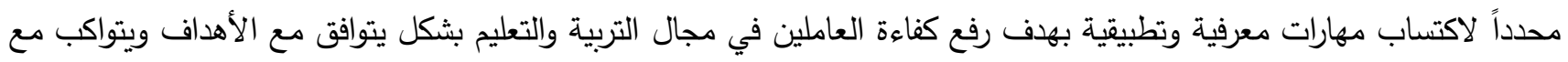

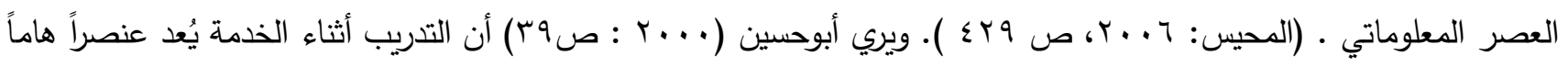

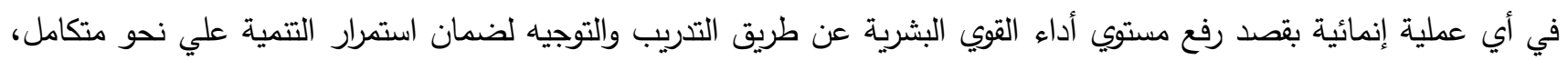
ويغلب علي مثل هذه البرامج اتساقها مع متطلبات العصر وأخذها بالمستحدثات والتغيرات المتلاحقة في شتى نواحي الحياة، وخاصة

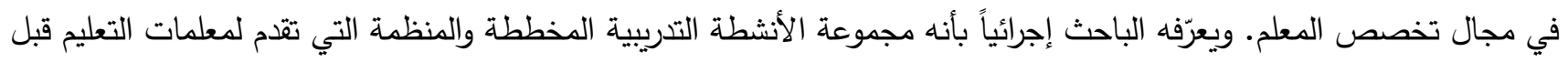

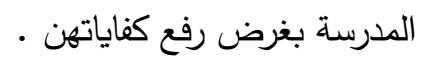

الكفاية (Competency)

عرّف كلٌ من (هاوسام) و(هوستون) الكفاية على أنها: "القدرة على إحداث نتائج متوقعة" ،وتعرّف (باتريشيا كاى) الكفايات بأنها: "الأهداف السلوكية المحددة بشكل واضح ودقيق للتدريس، وذلك في جوانب الخبرة التي تشتمل على المعارف والمهارات والاتجاهات، وأنها ضرورية لإظهار قدرة المعلم على التدريس الفعّال" ويشير (مرعى وآخرون) إلى تعريف الكفاية التعليمية بأنها

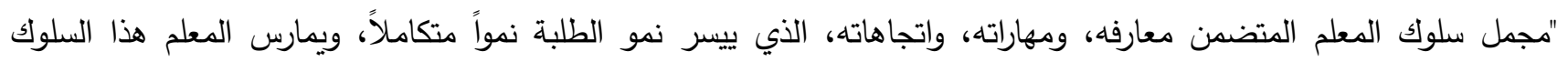
بمستوى معين من الإتقان" أي أن كفايات المعلم هي القدرات التي يحتاجها هذا المعلم لتمكنه من القيام بعمله بكفاءة وفاعلية، 
واقتدار وبمستوى معين من الأداء، وتشمل الكفايات المعرفية والأدائية والوجدانية.(الحيلة ا... ، ص ابr؟).وعليه فإن الأبعاد

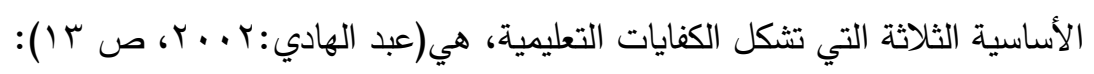
• المعرفي: والذي يتألف من مجموع العمليات المعرفية والقدرات العقلية الضرورية لأداء مهام الكفاية.

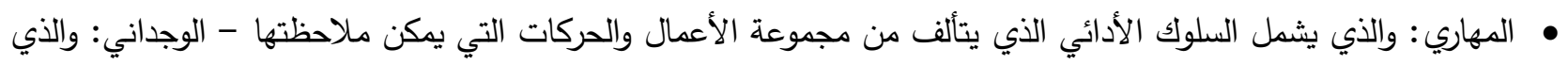

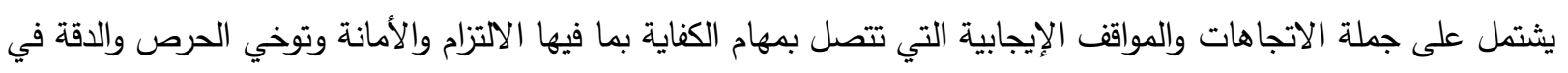
التنفيذ والتوظيف. ويعرّف الباحث الكفاية التعليمية إجرائياً بأنها: ( قدرة معلمة الروضة على تحقيق الأهداف التعليمية الدحددة سلفاً سواء

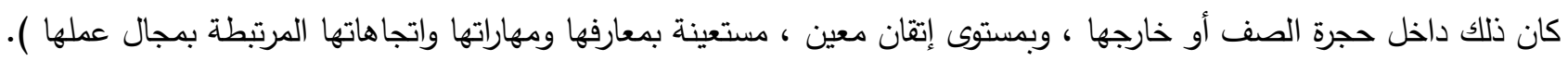
(الكفايات الأدائية (Performance Competency ):

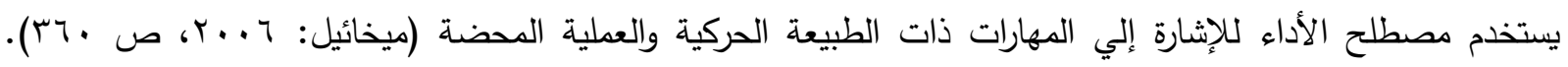
ويعرفها الباحث إجرائياً بأنها سلوكيات المعلمة التدريسية المتضمنة مهارات التخطيط والتتفيذ والتقويم للأنشطة التعليمية لتحقيق الأهداف التعليمية ، ويستدل عليها بالملاحظة ويمكن قياسها وتقويمها. ولاية الجزيرة: هي أحد ولايات السودان، تتميز بموقعها الاستراتيجي في وسط السودان، وتتوسط العديد من الولايات، في مساحة تبلغ

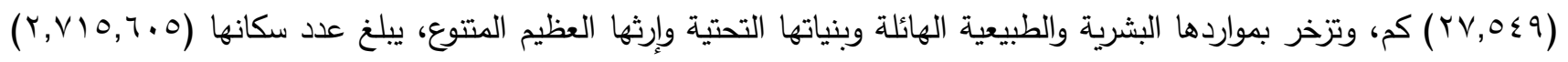
نسمه يمثلون 12.8\% من جملة سكان السودان ، وتضم (^) محليات (وحدات إدارية).( ويكيبيديا ، الموسوعة الحرة، ولاية الجزيرة).

ظهرت فكرة تدريب المعلمين أثناء الخدمة كرد فعل طبيعي لعجز معاهد تدريب المعلمين عن توفير العدد الكافي من المعلمين

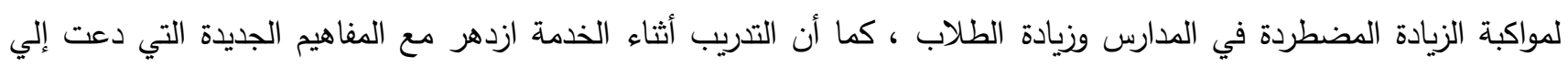

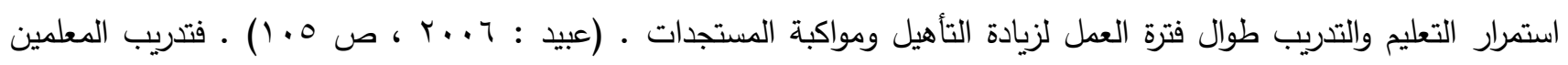
أثناء الخدمة أصبح ضرورة ملحة في ظل الواقع الراهن الذي يشهد تدنياً واضحاً في مستوي الخريجين في برامج الاعداد بكليات

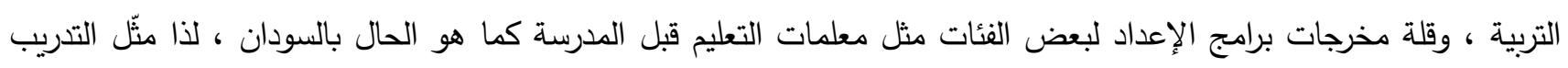

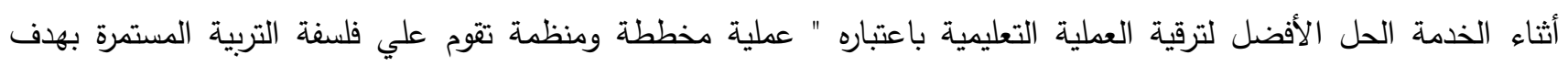

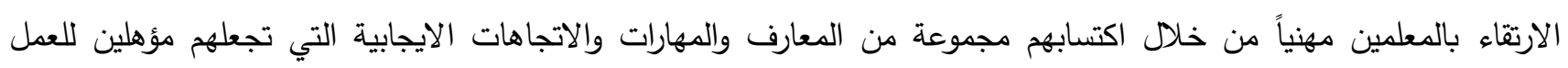

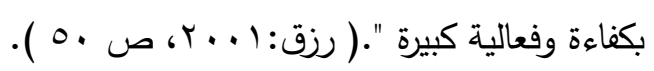

$$
\begin{aligned}
& \text { أهداف التدريب أثناء الخدمة : }
\end{aligned}
$$

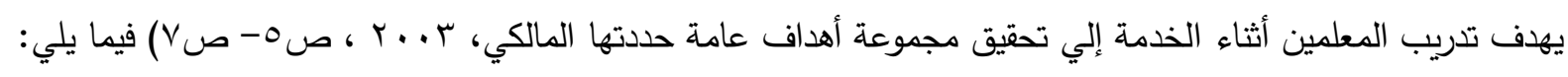
ا . ت تمية وعي المتدربين بما يستجد في حقل التربية وفهمهم للأسس التي بنى عليها.

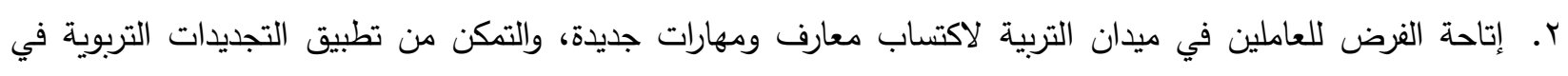
مجال تقويم عملية التعليم والتعلم. r. مواكبة المستجدات العلمية في مادة التخصص وأساليب البحث فيها بالإضافة إلى استخدام مصادر المعلومات المرتبطة بها بصورة جيدة. ع. تتمية الاتجاه نحو تقبل التغيير والاستعداد له، وبذل الجهد بوضع هذه التغيرات موضع الاختيار والتجريب والاستفادة من ذلك في عملية التطوير · 
ه. تعريف المتدبين بما ينبغي أن يؤدوه من أدوار وتزويدهم بالمعارف والدهارات التي تككهم من القيام بتلك الأدوار بفاعليه وكفاية.

آ. تتمية وعي المتدربين لتفهم العلاقة الوثيقة بين النظرية والتطبيق في مجال التعليم والتعلم.

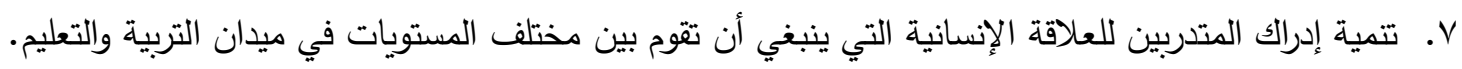

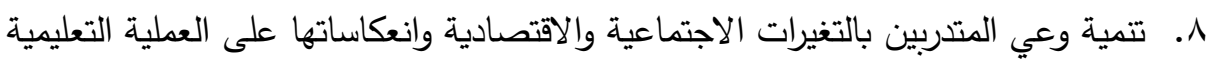
9. . الاستفادة من خبرات ومعارف ومهارات العاملين في ميدان التربية والتعليم.

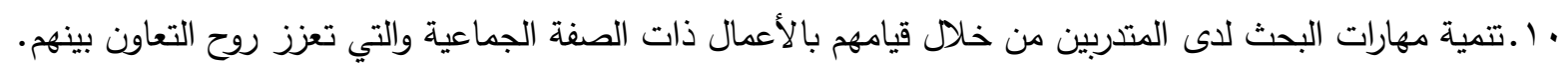
المبادئ الأساسية لبرامج تدريب المعلمين أثناء الخدمة:

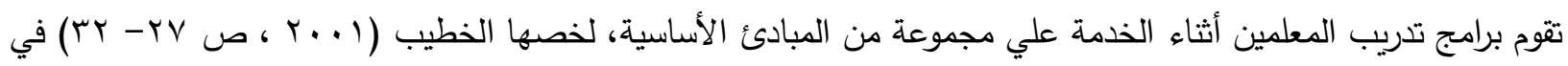

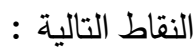

$$
\begin{aligned}
& \text { • اعتماد إطار أو نموذج نظري للتدريب. } \\
& \text { وضوح وتحديد أهداف برنامج التتريب. } \\
& \text { • تلبية الحاجات المهنية للمتدربين. } \\
& \text { ه المرونة وتعدد الاختيارات في برنامج التدريب. } \\
& \text { توجيه برنامج تريب المعلمين نحو الكفايات التعليمية. }
\end{aligned}
$$

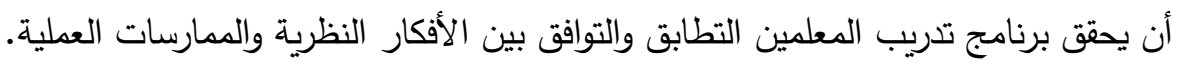$$
\text { أستمرارية عملية تدريب المعلمين. }
$$

• • أن يمكّن البرنامج المتدربين من تحقيق ذواتهم.

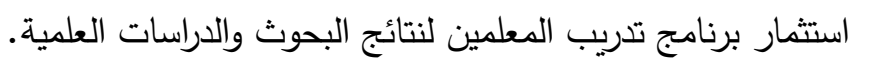

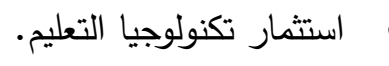
تقريد التعليم.

$$
\text { اعتماد منهج التتريب المتعدد الوسائط. }
$$

مثلت تلك المبادئ المرتكزات الأساسية التي اعتمد عليها الباحث في بناء البرنامج التندريبي المقترح لتتمية الكفايات التعليمية

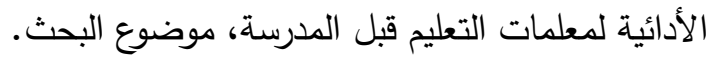

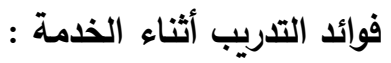

للتتريب أثناء الخدمة فوائد عظيمة بالنسبة للعاملين في شتي المجالات ، حيث يتم من خلاله رفع مستوي كفاياتهم المهنية

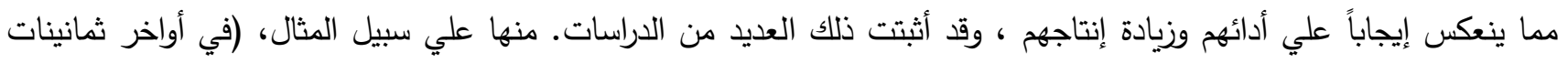

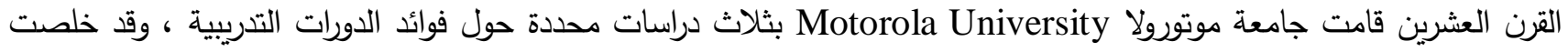

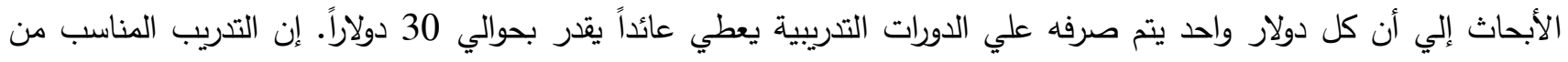

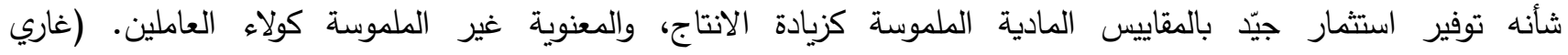

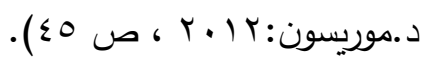
أما فوائد الدورات التدريبية أو التتريب أثناء الخدمة بالنسبة للمعلمين فهي أعظم. لأن ما يشهده العالم اليوم من تطورات كثيرة

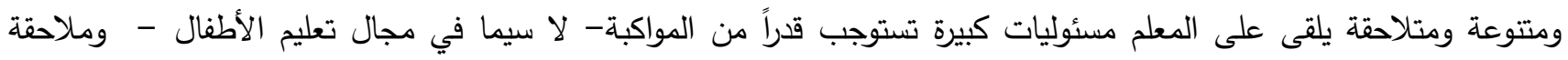

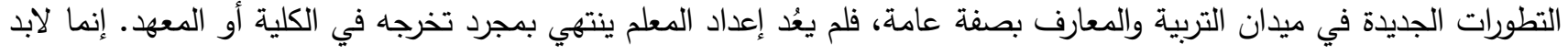
أن يكتمل هذا الإعداد أثناء قيامه بعمله، فالتربية المهنية المستمرة للمعلمين عملية مهمة من أجل تتميتهم الثخصية وتنمية مهاراتهم وفعالياتهم في التندريس. 
جاء تأكيد علماء التربية علي أهمية التتريب أثناء الخدمة للمعلمين منذ زمن بعيد، وتبلور ذلك في المؤتمر العالمي للتربية الذي عقد في جنيف عام (90V (م) حيث أكد المؤتمر على أهمية التدريب المستمر أثناء الخدمة، وأعطى أهمية خاصة للحاجة إلى وتى

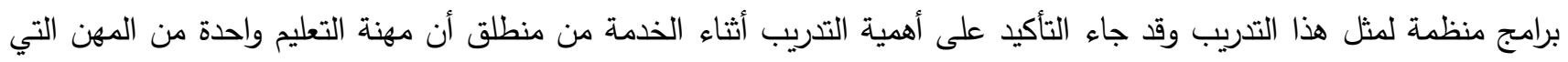

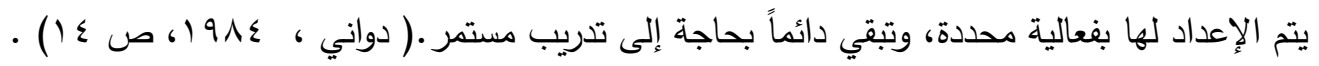

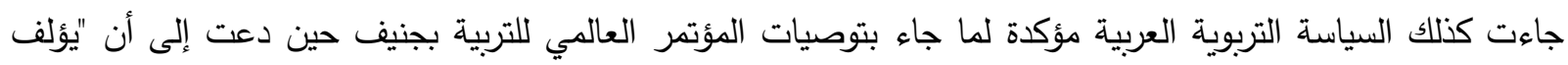

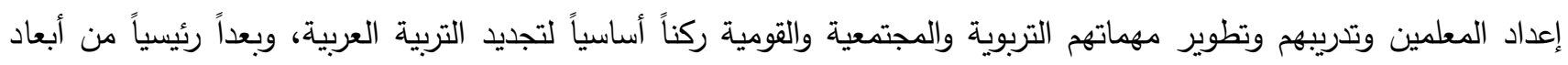

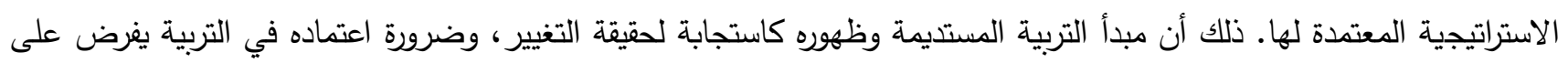
المعلمين أن يكونوا طلائع في تطبيقه وفي استثماره في تطوير مهامهم، وتطور المعرفة العلمية والتربوية، وفيما يشكو منه الجهاز التعليمي من نقص في التدريب، يوجب بإلحاح تطوير أنماطه ونماذجه لتلائم مهنة التعليم" (المنظمة العربية للتربية والثقافة والعلوم، وفئه

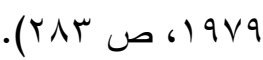

يمكن تلخيص أهم العوامل والمتغيرات التي جعلت من التأهيل التربوي أثناء الخدمة أمراً مهماً ومطلباً ملحاً في النقاط التالية

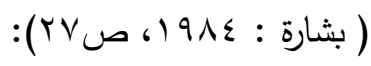

ا ـ الانفجار المعرفي الذي أصبح من سمات العصر المميزة، والذي نتج عن الثورة العلمية والتكنولوجية التي يشهدها العالم اليوم،

مما جعل الإلمام الكامل والإحاطة الموضوعية بما يستجد من معلومات في ميدان التخصص، أمراً يكاد يكون مستحيلاً.

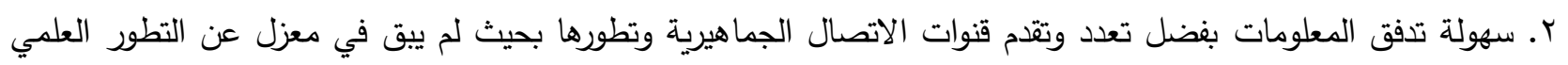

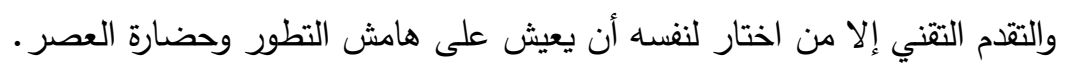

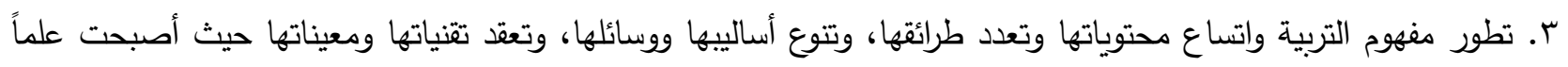
قائماً بذاته له نظرياته وأصوله ومنطلقاته العلمية، ومناهجه البحثية ومعالجاته الإحصائية.

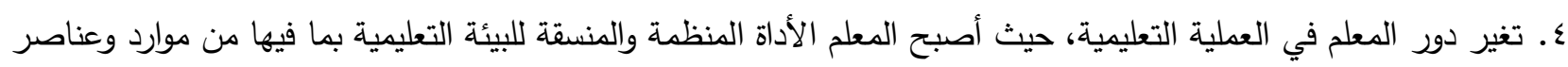

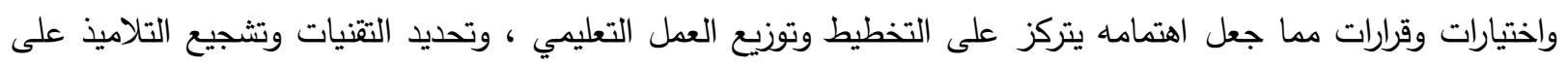
الاستقلال وملاحظة تقدمهم الدراسي وتثخيص مواقع الضعف ومواطن الخلل في عملية التعليم والتعلم. مبررات التربيب أثناء الخدمة :

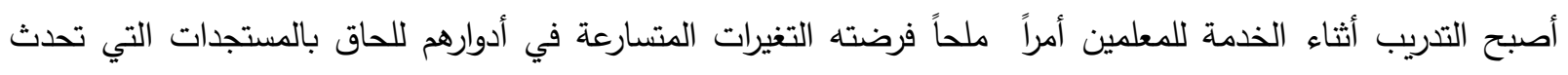

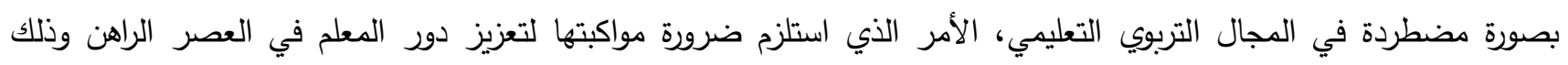

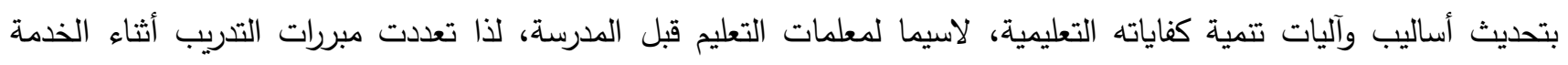

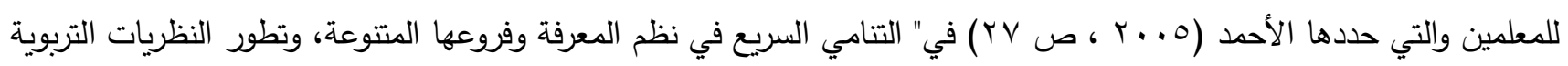
وتطوير المناهج التربوية والعلوم وطرق تدريسها وتطور التقنية ووسائل الاتصال، إلي جانب معالجة النقص الحاصل في في فترة الاعدئ العداد

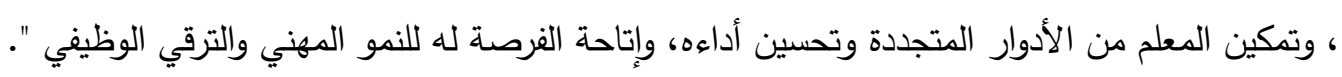
التصميم التعليمي :

تسبق مرحلة البناء عادة مرحلة التصميم، فهي التي يتم فيها تأطير الأفكار المجردة في صورة عمليات من خلال

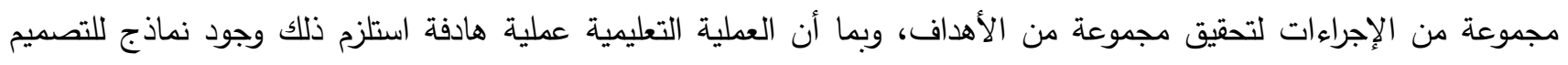
التعليمي لتحقيق تلك الأهداف بدرجة عالية من الجودة، ( فالنموذج عبارة عن طريقة لتمثيل الأحداث والوقائع والعلاقات بينها، وذلك دئك

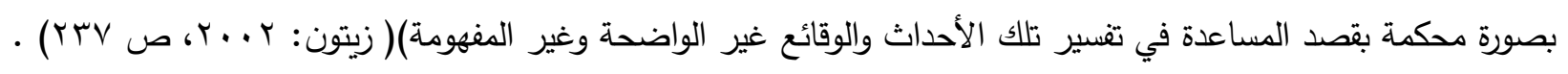
أما نموذج التصميم التعليمي فيعرف بأنه (تصور عقلي مجرد لوصف الإجراءات والعمليات الخاصة بتصميم التعليم

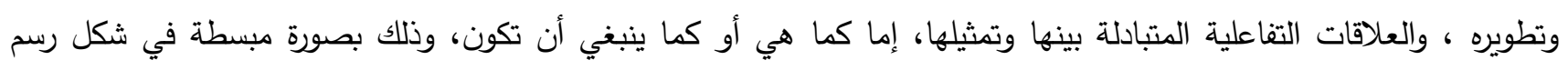


خطي مصحوب بوصف لفظي يزودنا بإطار عمل توجيهي لهذه العمليات والعلاقات وفهمها، وتنظيمها، وتفسيرها، وتعديلها،

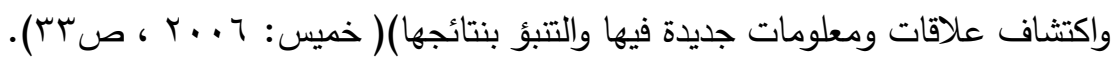

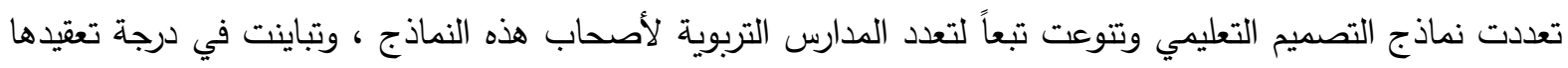
وذلك لتداخل العناصر المكونة لتلك النماذج. ولا توجد طريقة مثلي واحدة لتصميم التعليم. إن تطبيق عملية تصميم التعليم من شأنه أن يقلل الاعتماد علي الحدث والتجريب والخطأ في التخطيط، مع ذلك فإن فئن عملية تصميم التعليم لم ترق بعد إلي مستوي الدقة العلمية، فهناك عدة طرق يمكن أن توصل للأهداف والغايات نفسها. (غاري

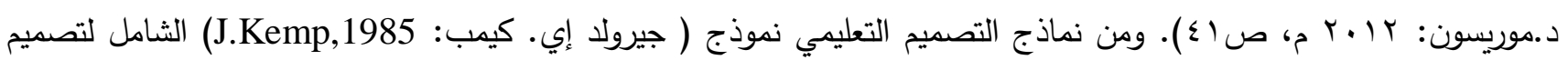
التعليم والتدريب. وهو النموذج الذي اعتمده الباحث في تصميم البرنامج التدريبي موضوع ادئ البحث.

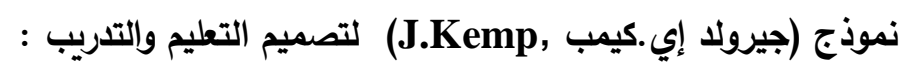
يتميز هذا النموذج من بين نماذج تصميم التعليم الأخرى بأنه جاء شاملاً لجميع العناصر الرئيسة في عملية التخطيط للتدريب ويتكون من عشرة مكونات أو موضوعات فرعية ، يمكن وصفها بإيجاز علي النحو التالي (J.Kemp,1985:11)

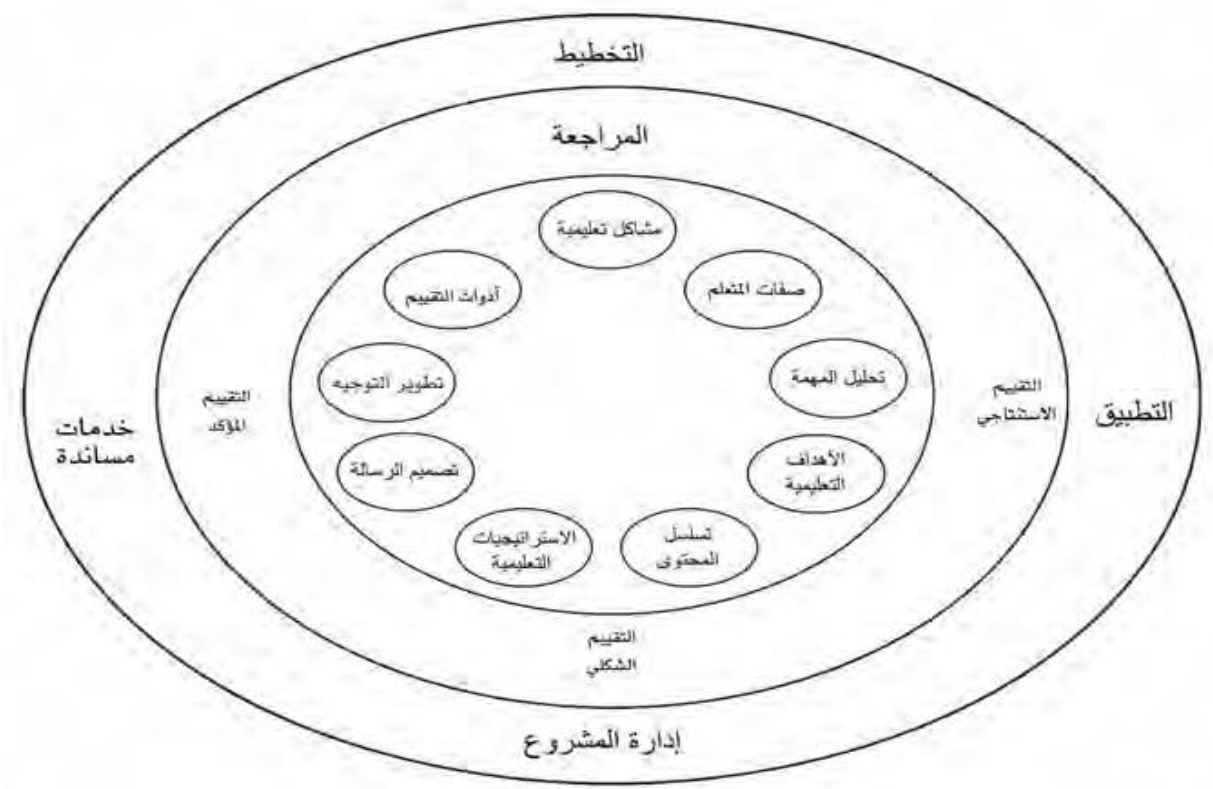

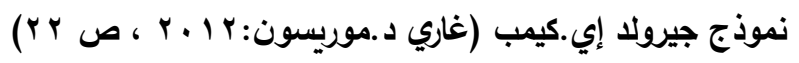

أسباب استخدامهه :

وجد نموذج كيمب البيضاوي الشكل اهتماماً كبيراً من التربوين والعاملين في ميدان التصميم التعليمي لعدة أسباب منها

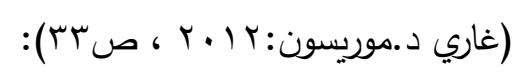

ا. الترتيب الذي نتعرف من خلاله علي كل عنصر علي حده غير محدد سلفاً، لهذا السبب تم اعتماد هذا الثكل، إذ أنه ليست له نقطة بداية. r. ل ا ترتبط العناصر ببعضها البعض بخطوط وأسهم، فقد يدل الربط علي ترتيب تسلسلي طولي ، والهدف من ذلك هو

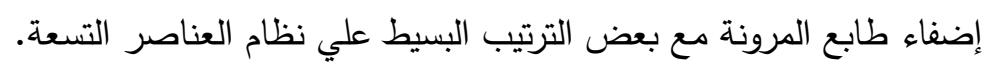

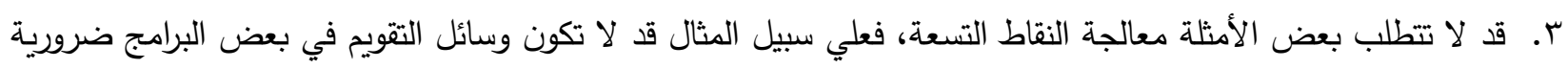
(كما هو الحال في هذا البرنامج). ع. ـقيقة الوضع أو الحالة هي التي تحدد في أغلب الأحيان حدود وقيود التصميم التعليمي الذي نقوم به. ه. وجود اعتماد واتكال متبادل ومرن بين العناصر التسعة ، فالقرارات المتعلقة بأحدها تؤثر حتماً في بالقرارات الأخرى. 
استرشد الباحث في هذا البحث بعدد من الدراسات السابقة العربية والأجنبية ذات الصلة بموضوع البحث منها الدراسات التالية:

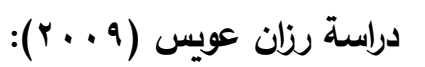

الهدف من الدراسة بناء برنامج لتدريب معلمات رياض الأطفال علي تتمية مهارات التفكير لدي أطفال الروضة، وقياس

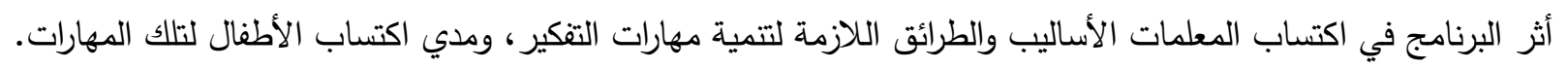
لتحقيق أهداف البحث استخدمت الباحثة الأدوات التالية: ( البرنامج التدريبي المقترح، بطاقة ملاحظة لرصد مهارات

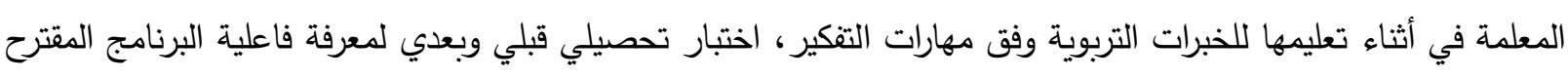

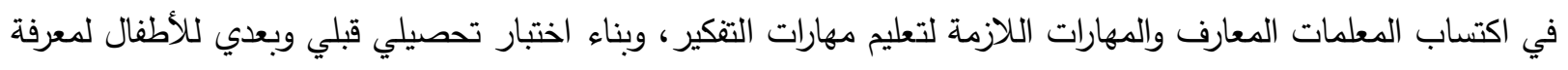
مدي اكتسابهم لمهارات التفكير • شملت عينة البحث مجموعتين من الأطفال، المجموعة التجريبية وهم الاطفال الذين تدربت ولتباء معلماتهم في البرنامج التدريبي وعددهم (99 (19) طفلاً وطفلة من الفئة الثالثة برياض الأطفال، وتكونت المجموعة الضابطة من (ع (1) طفلاً وطفلة لم تتدرب معلماتهم في البرنامج المقترح، إضافة إلي عينة المعلمات الذين حضروا البرنامج التدريبي وعددهن (0 1 ) معلمة من الرياض الخاصة والرياض التابعة لوزارة التربية ووزارة الإدارة المحلية بدمشق لفئ.

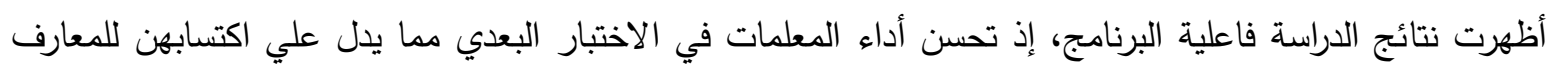

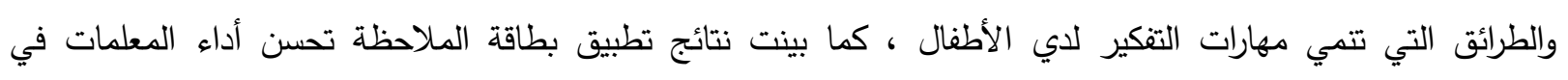
الممارسة العملية لتطبيق مهارات التفكير، وأظهرت الدراسة وجود فروق ذات ذات دلالة إحصائية بين متوسطي درجات المجموعتين الضابطة والتجريبية في التطبيق البعدي لاختبار مهارات التفكير لصالح المجموعة التجريبية.

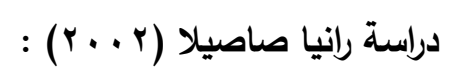

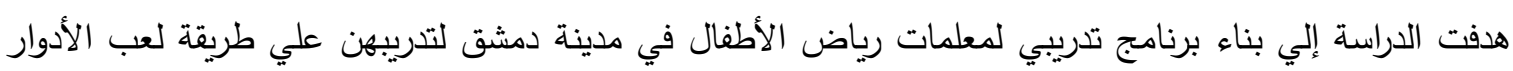

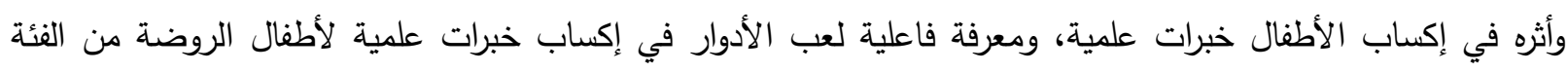

أكدت النتائج علي فاعلية طريقة لعب الأدوار في إكساب الأطفال خبرات علمية، ووجود فرق ذي دلالة إحصائية بين

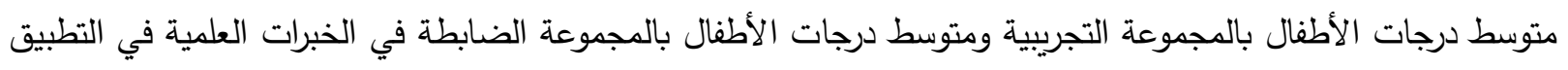
البعدي لصالح أطفال المجموعة التجريبية ، ووجود فرق ذي دلالة إحصائية بين متوسط درجات أطفال المجموعة التجريبية في التطبيق القبلي ومتوسط درجاتهم في التطبيق البعدي، أي أن الفرق يعزي لتأثير طريقة لعب الألة الأدوار .

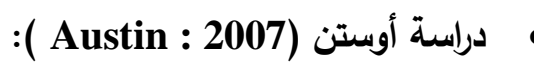

هدفت إلي رصد التحديات الاجتماعية والثقافية المعاصرة التي تواجه المعلم في مؤسسات ومعاهد إعداد المعلمين في كلية المعلمين (بتايبييه) بتايوان، وأوجه القصور في إعداد المعلم في ضوء التغيرات الاجتماعية والاقتصادية والصناعية

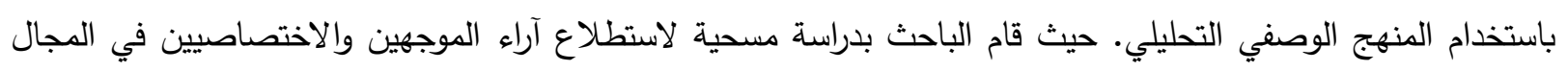

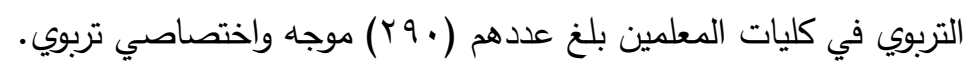
توصلت الدراسة إلي مجموعة من النتائج أهمها ، تحديد أهم الاحتياجات التدريبية علي اعتبار أن الاحتياجات التدريبية ماهي إلا مجموعة من الكفايات والمهارات المكونة لها والتي تتعلق بتدريب المعلم علي الجوانب المهنية المتعلقة بأدائه

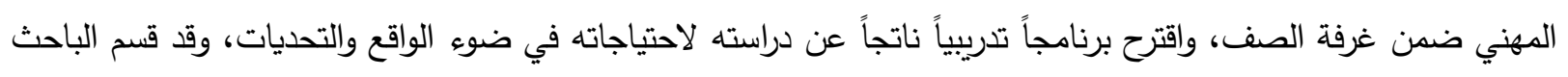

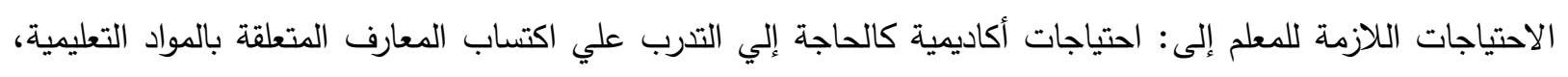

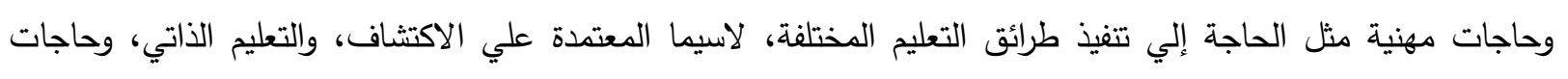
ثقافية كالحاجة إلي الاطلاع علي المعارف الثقافية العامة. 


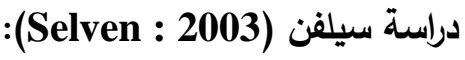

هدفت إلي تحديد الكفايات التعليمية الأدائية الأساسية لمعلمات رياض الأطفال بولاية بنسلفانيا الأمريكية ومدي توافرها

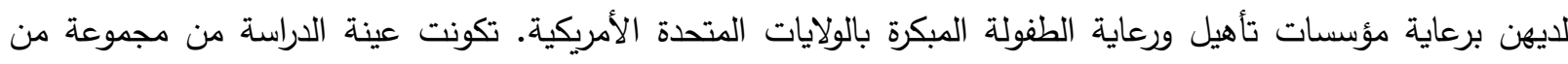

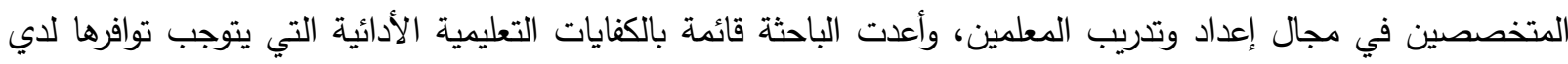
معلمة روضة الأطفال استناداً للمصادر التالية لاشتقاق تلك الكاب الكفايات التعليمية: • • ملاحظة أداء بعض المعلمات برياض الأطفال. • الاطلاع علي بعض المراجع والدراسات التي تناولت موضوع الكفايات التعليمية بصورة عامة وكفايات معلمات رياض

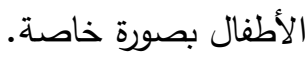
• التعرف علي آراء بعض العاملين والمهتمين بتربية الطفل قبل المدرسة وإعداد المعلمين. توصلت الباحثة إلي قائمة

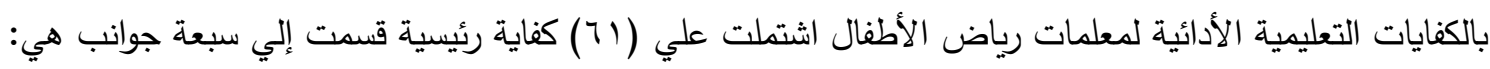

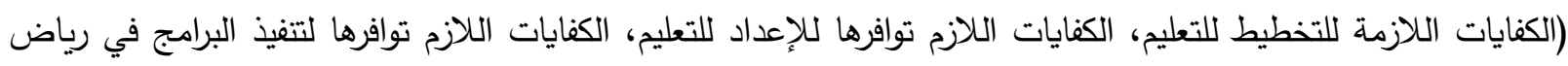

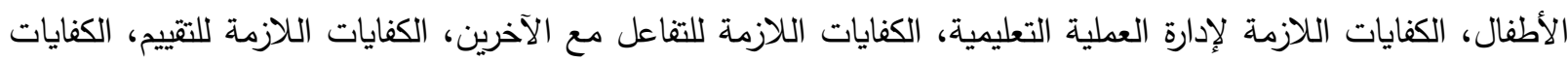

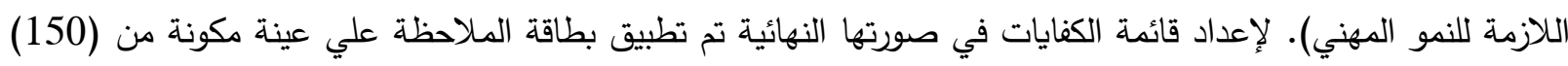

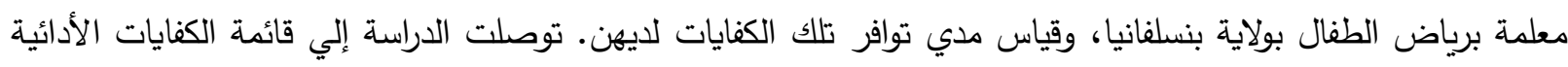

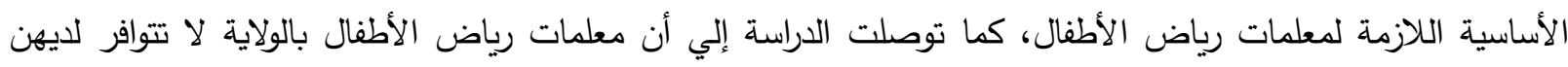

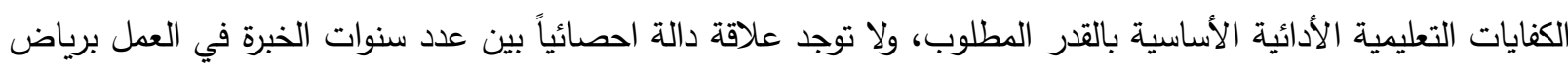

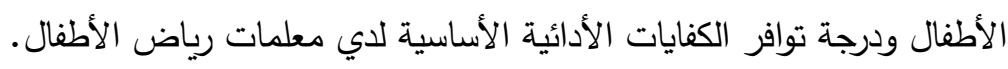

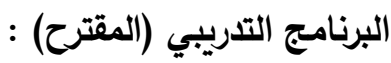

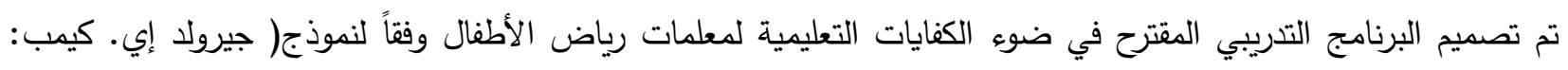

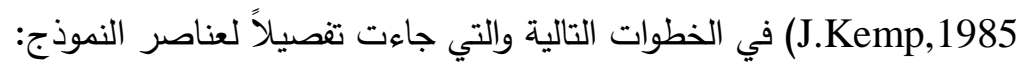

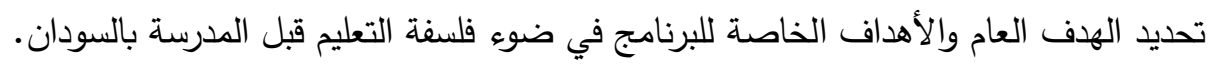

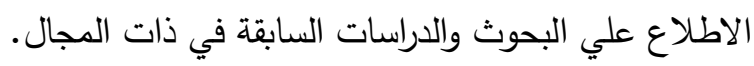

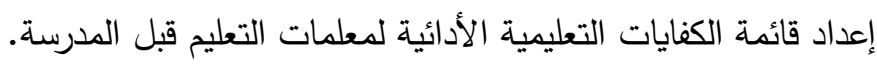
• تصميم استمارة الملاحظة ( أداة تقويم الكفايات الأدائية ). تحديد الاحتياجات التدربية لمعلمات التعليم قبل الدرسة. اختيار النموذج التدريبي المناسب للبرنامج. تصميم البرنامج التدريبي. • تحديد محتوي البرنامج والأنشطة التدريبية. تحديد طرائق تتفيذ البرنامج.

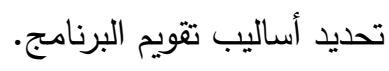

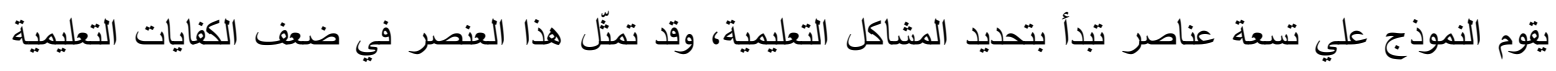

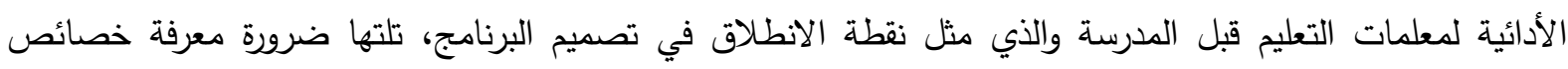

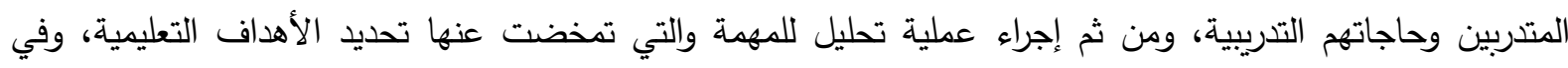

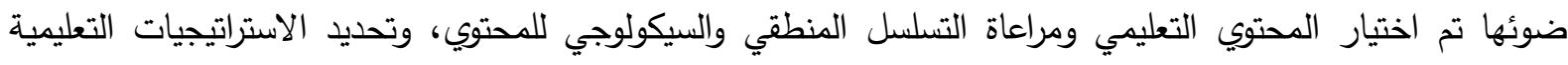


لتتفيذ البرنامج التدريبي متبوعاً بتصميم الرسالة والتوجيه المستمر أثناء التنفيذ، وانتهاءً باختيار أدوات التقويم والتي تمثلت

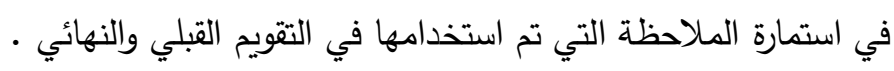
عناصر النموذج التسعة يتم تحقيقها تحت مظلة المراجعة المستمرة للبرنامج من خلال التقييم الاستتاجي والتقييم

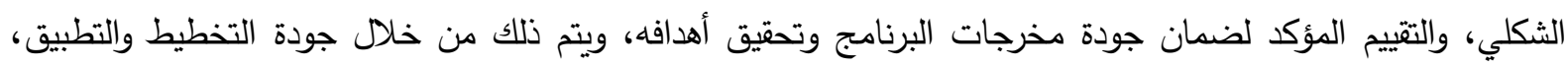
وحسن إدارة تتفيذ البرنامج التدريبي بتوظيف كافة الخدمات المساندة.

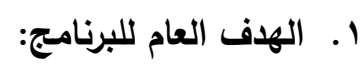
تتمية الكفايات التعليمية الأدائية لمعلمات التعليم قبل المدرسة

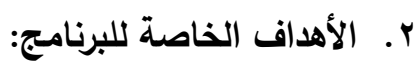
• رفع درجة امتلاك معلمات التعليم قبل المدرسة للكفايات الأدائية المتعلقة بالتخطيط للتعليم. • رفع درجة امتلاك معلمات التعليم قبل المدرسة للكفايات الأدائية المتعلقة بتتفيذ البرامج التعليمية. • رفع درجة امتلاك معلمات التعليم قبل المدرسة للكفايات الأدائية المتعلقة بإدارة العملية التعليمية.

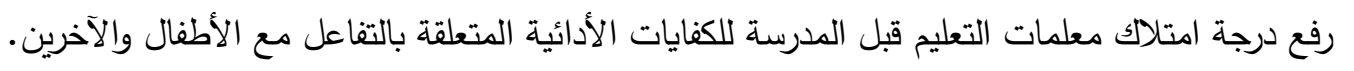

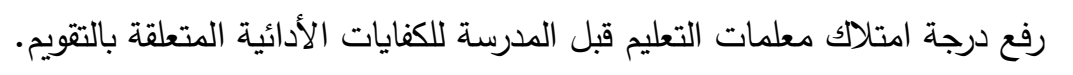

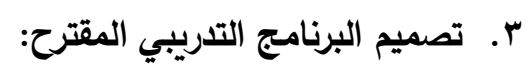
بعد تحديد فلسفة وأهداف البرنامج في المستويين العام والخاص ، قام الباحث مسترشداً بما سبق من دراسات بإعداد قائمة الكفايات التعليمية الأدائية الواجب توافرها لدي معلمة التعليم قبل المدرسة، ومن ثم تجهيز استمارة الملاحظة بغرض التقويم القبلي للرجة امتلاك معلمات التعليم قبل المدرسي للكفايات الأدائية حيث تم تطبيقها بواسطة الباحث بمعاونة الأخوات بالتوجيا الفني بالمحلية. وأظهرت النتائج تدني واضح في درجة امتلاك المعلمات للكفايات الأدائية، وقد تمخض عن ذلك تحديد الاحتياجات التدريبية لمعلمات التعليم قبل المدرسة في مجال الكفايات الأدائية. قام الباحث في ضوء تحديد الاحتياجات التدريبية للمعلمات بتصميم البرنامج التدريبي المقترح مستعيناً بما سبق من دراسات في هذا المجال، حيث تم اختيار النموذج التدريبي الملائم لأهداف البرنامج الذي سيقوم عليه تصميم البرنامج، وقد تم اختيار نموذج ( جيرولد إي. كيمب: J.Kemp,1985) لبساطته ومرونته في استيعاب المستجدات التي لتي

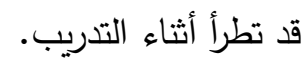
تحقيقاً لأهداف البرنامج تم اختيار المحتوي التدريبي ومن ثم تخطيطه وتتظيمه وفقاً لضوابط تتظيم المحتوي من حيث التسلسل المنطقي والسيكولوجي في ضوء النموذج المعتمد لتصميم البرنامج، وقد روعي في اختيار المحتوي الثمولية لكافة الموضوعات والأنشطة التعليمية التي ترفع من درجة امتلاك المتدربات للكفايات التعليمية الأدائية، مع وع كراعاة التوازن بين الجانبين النظري والتطبيقي. ؛. ـ محتوي البرنامج التدربي المقترح: يتكون البرنامج من ستة محاور يتم من خلالها تتاول الكفايات التعليمية الأدائية لمعلمة التعليم قبل المدرسة، وهي: (التعليم قبل المدرسة، منهج التعليم قبل المدرسة، سيكولوجية طفل الروضة، أنشطة الروضة، التبنة الوسائل التعليمية، التدريب

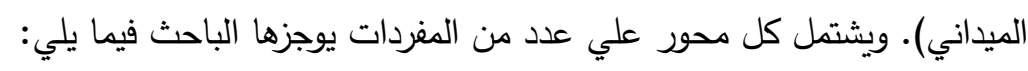

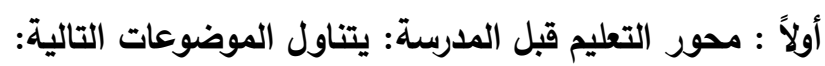

$$
\text { فلهفة ومفهوم التعليم قبل المدرسة بالسودان. }
$$


• البيئة التعليمة بروضة الأطفال (الموقع، المباني، الأثاثات، التجهيزات، العاملون بالروضة).

• واقع التعليم قبل المدرسة بالسودان عامة وولاية الجزيرة بصفة خاصة.

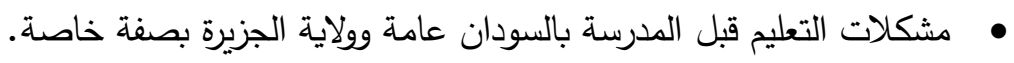

ثانياً: محور منهج التعليم قبل المدرسة: يحتوي هذ المحور علي الموضوعات التالية:

$$
\begin{aligned}
& \text { فلسفة منهج التعليم قبل المدرسة. } \\
& \text { أهداف منهج التعليم قبل المدرسة. } \\
& \text { • طرائق تدريس واستراتيجيات تتفيذ منهج التعليم قبل المدرسة. }
\end{aligned}
$$

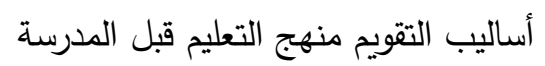

$$
\begin{aligned}
& \text { ملاحظات حول منهج التعليم قبل الددرسة. }
\end{aligned}
$$

صعوبات تتفيذ منهج التعليم قبل المدرسة بالسودان عامة وولاية الجزيرة بصفة خداصة فئة.

ثالثاً: محور سيكولوجية طفل الروضة: ويشمل الموضوعات التالية:

• مراحل النمو، خصائص النمو في مرحلة الطفولة المبكرة.

• العوامل المؤثرة في سيكولوجية طفل الروضة.

تعليم طفل الروضة.

• صعوبات التعلم في مرحلة الطفولة المبكرة.

• المشكلات السلوكية لطفل ما قبل المدرسة.

اكتشاف الأطفال ذوي الاحتياجات الخاصة .

رابعاً: محور الوسائل التعليمية: ويتناول الموضوعات التالية التالية:

• مفهوم الوسيلة التعليمية.

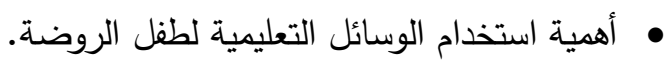

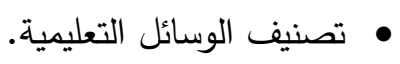

ه اختيار الوسيلة التعليمية وطرائق إعدادها وعرضها لطفل الروضة.

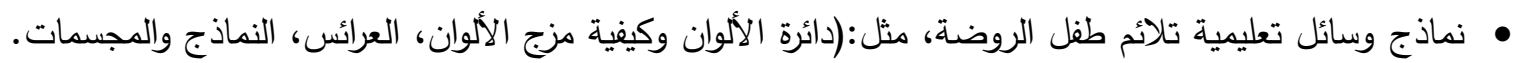

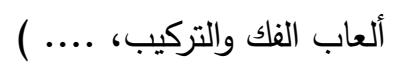

خامساً: محور أنثطة الروضة: ويتناول الموضوعات التركاب، التالية:

$$
\begin{aligned}
& \text { أنشطة الروضة ( مفهومها، أهميتها، أهدافها). } \\
& \text { بداية اليوم الدراسي( استقبال الأطفال). } \\
& \text { الطابور الصباحي. } \\
& \text { تتفيذ الأنشطة التعليمية(خبرات المنهج، الأركان). } \\
& \text { تنفيذ الزيارات العلمية والرحلات. } \\
& \text { تتفيذ الألعاب الفردية والجماعية. } \\
& \text { التواصل مع أسرة الطفل. } \\
& \text { التعاطي مع الحالات الطارئة. } \\
& \text { نهاية اليوم الدراسي( وداع الأطفال). }
\end{aligned}
$$




\section{سادساً: محور التدريب العملي:}

يحوي هذا المحور عدداً من الأنشط التطبيقية (الكفايات التعليمية الأدائية) التي تقوم بها الدارسة (المتدربة) في الحقل مباشرة (روضة الأطفال). بعد تعريف الدارسات بأهداف ومحتوي هذا المحور من خلال التدريب العملي

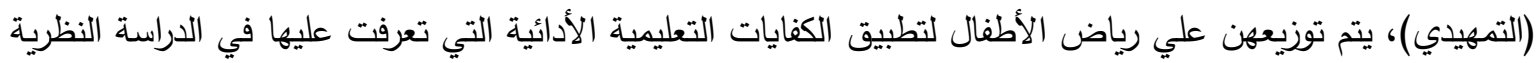
للبرنامج، ويتم ذلك بحضدر يوم دراسي كامل بروضة الأطفال بدءاً باستقبال الأطفال، مروراً بالأنشطة التعليمية

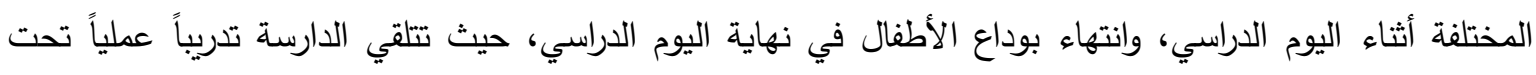
إشراف موجهين متخصصين ، يعقبه حلقة نقاش (تدريب عملي ختامي) لتقييم الأداء.

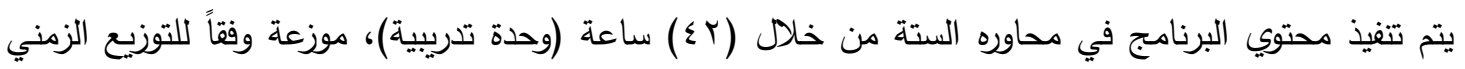

جدول ( ) يوضح الجدول الزمني للبرنامج التدريبي المقترح

\begin{tabular}{|c|c|c|c|c|}
\hline \multirow[b]{2}{*}{ مجموع الساعات } & \multicolumn{2}{|c|}{ الزمن المقرر بالساعات } & \multirow[b]{2}{*}{ اسم المحور } & \multirow[t]{2}{*}{ s } \\
\hline & عملي & نظري & & \\
\hline 6 & - & 6 & التعليم قبل المدرسة & \\
\hline 6 & - & 6 & منهج التعليم قبل المدرسة & \\
\hline 6 & - & 6 & سيكولوجية طفل الروضة & \\
\hline 8 & 2 & 6 & أنشطة الروضة & \\
\hline 8 & 2 & 6 & الوسائل التعليمية & \\
\hline 8 & 8 & - & التدريب العملي & \\
\hline 42 & 12 & 30 & المجموع & \\
\hline
\end{tabular}

\begin{tabular}{|c|c|c|c|c|c|c|c|c|}
\hline$r+r$ & استراحة & $\begin{array}{l}1 r: \varepsilon \\
1:\{.\end{array}$ & $\begin{array}{l}11: \varepsilon . \\
\mid r: \varepsilon .\end{array}$ & $\begin{array}{l}1 .: \varepsilon . \\
11: \varepsilon .\end{array}$ & استراحة & $1 .-9$ & $9-1$ & الأيام \\
\hline التعليم قبل المدرسة & & منهج التعليم قبل & سيكولوجية طفل & التعليم $\quad$ المدرسة & & سيكولوجية طفل & التعليم $\quad$ المدرسة & الأحد \\
\hline التعليم قبل المدرسة & & سيكولوجية طفل & التعليم $\quad$ المدرسة & المدهج التعليم قبل & & التعليم قبل المدرسة & سيكولوجية طفل & الاثنين \\
\hline منهج التعليم قبل الددرسة & & سيكولوجية طفل & وسائل تعليمية & أنشطة الروضة & & سيكولوجية طفل & منهج التعليم قبل & الثلاثاء \\
\hline أنشطة الروضة & & وسائل تعليمية & منهج التعليم قبل & وسائل تعليمية & & منهج التعليم ققبل & أنشطة الروضة & الأربعاء \\
\hline أنشطة الروضة & & وسائل تعليمية & أنشطة الروضة & أنشطة الروضة & & وسائل تعليمية & وسائل تعليمية & الخميس \\
\hline تدريب عملي (تمهيدي) & & تدريب $\quad$ عملي & وسائل تعليمية & وسائل تعليمية & & أنشطة الروضة & أنشطة الروضة & السبت \\
\hline تدريب عملي ختامي & & تدريب عملي & تدريب عملي & تدريب عملي & & تدريب عملي & تدريب عملي & الأحد \\
\hline
\end{tabular}


تحقيقاً لصدق محتوي البرنامج وللتحقق من ملاءمة المحتوي للأهداف المحددة، تم عرض البرنامج علي لجنة من

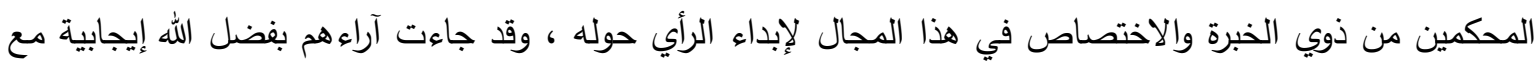

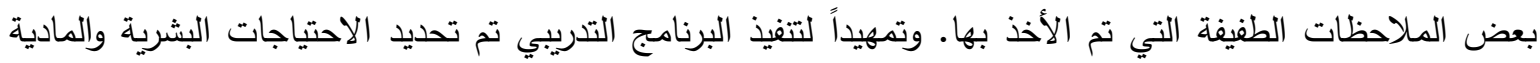

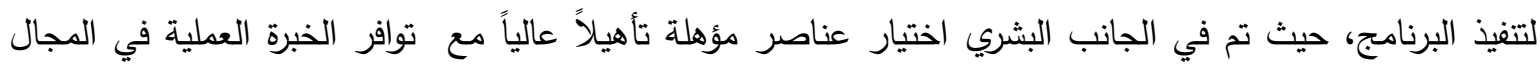

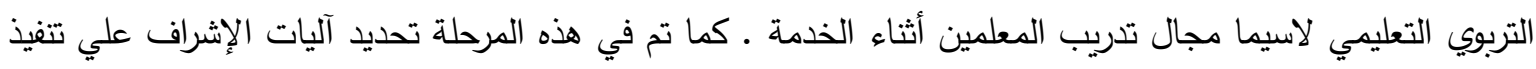

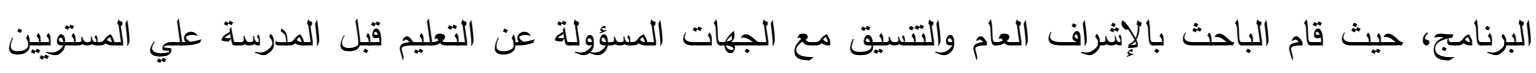

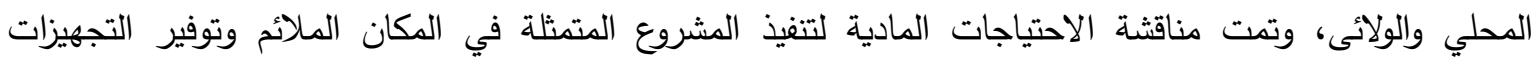
اللازمة، ومن ثم الاتفاق علي تفاصيل الجدول الزمني لتنفيذ البرنامج التدريبي والذي أُتفق علي أن تكون فترة التنفيذ أسبوعاً واحداً لظروف سكن بت الاتفاق عضي لعاهيل المتدربات بمناطق تبعد عن مقر تتفيذ البرنامج.

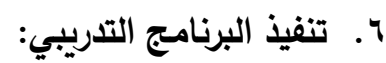

بتوفيق من الله تم تنفيذ البرنامج وفقاً للخطة المرسومة بالرغم من وجود بعض المعيقات التي تم تجاوزها بتضافر

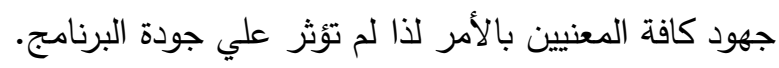

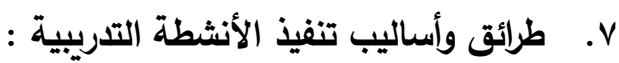

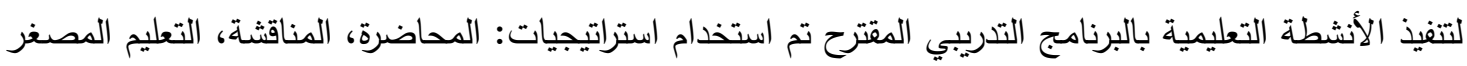
التعليم التعاوني، العروض العملية، العصف الذهني. ^. المباني والتجهيزات وإلمواد: تم تتفيذ البرنامج التدريبي بقاعة محاضرات مهيأة بشكل جيد، مجهزة بجهاز عرض البيانات(Data Show)، كما

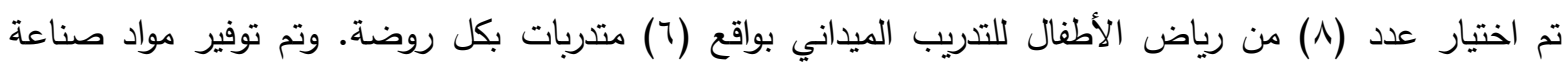

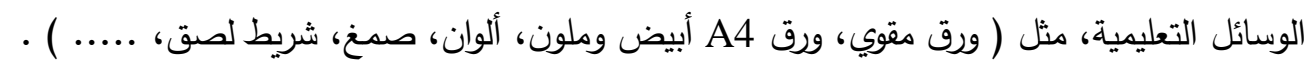
9 . أساليب تقويم البرنامج:

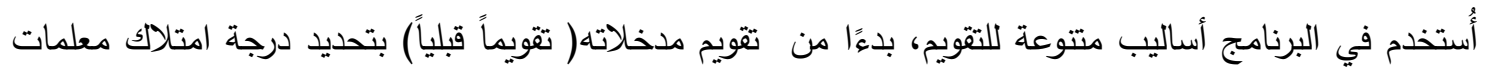

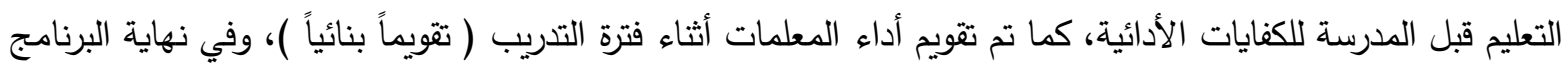

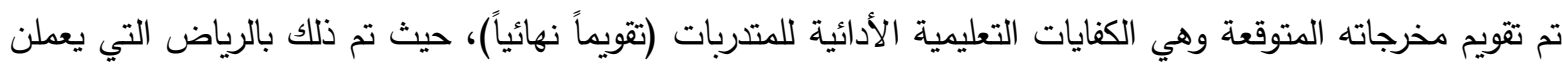

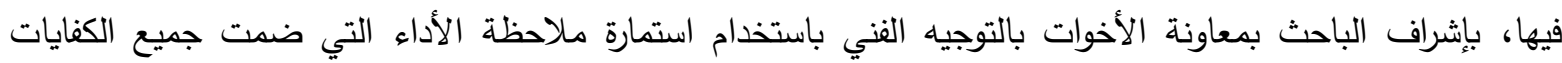

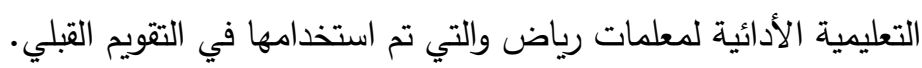

\section{في خاتمة هذا البحث يوصي الباحث بالآتي:}

• اعتماد التدريب أثناء الخدمة كآلية فعّالة لتتمية كفايات جميع العاملين في الحقل التربوي التعليمي، لاسيما المعلمين. تفعيل دور معاهد التدريب أثناء الخدمة في تتمية كفايات العاملين في الحقل التربوي، ورفدها بالكوادر البشرية المؤهلة،

$$
\text { وتوفير الميزانيات اللازمة للتدريب. }
$$

• إعداد خطة عامة للتدريب أثناء الخدمة لمعلمات التعليم قبل المدرسة علي مستوي السودان.

•قترح الباحث إجراء مزيداً من الدراسات المستقبلية المكملة للدراسة الحالية، مثل: بناء برنامج تدريبي لتتمية الكفايات التعليمية المعرفية لمعلمات التعليم قبل المدرسة.

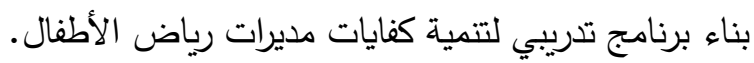


ا. أبو حسين، محمد كمال ( . . ب): برنامج مقترح للتدريب الصفي لمعلمي التعليم الأساسي أثناء الخدمة في ضوء فلسفته، رسالة ماجستير غير منشورة ، كلية التربية ، جامعة الاسكندرية.

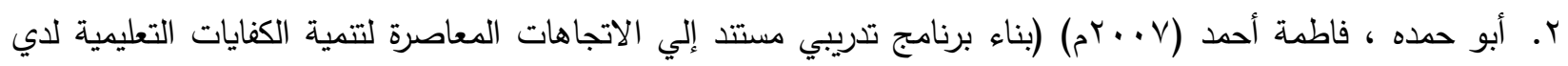

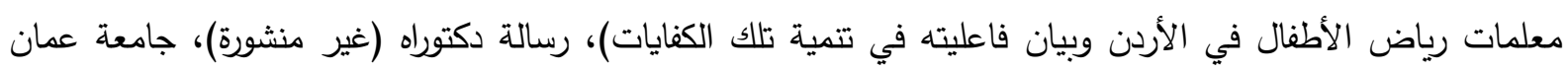
العربية للدراسات العليا، عمان، الأردن. r. إدارة الإحصاء والتخطيط التربوي ( r إ. rم)، وزارة التربية والتعليم، ولاية الجزيرة، السودان.

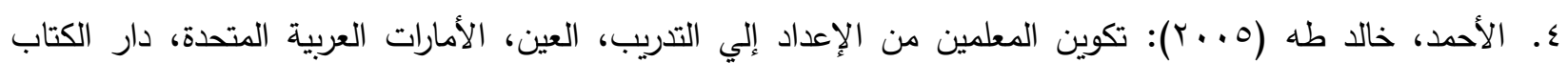

$$
\text { الجامعي. }
$$

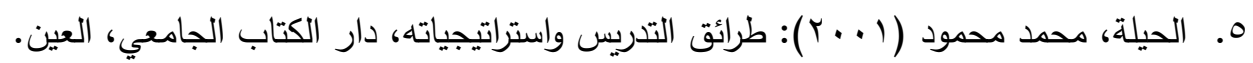

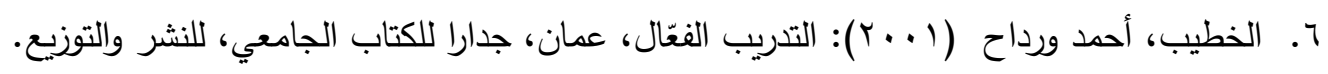

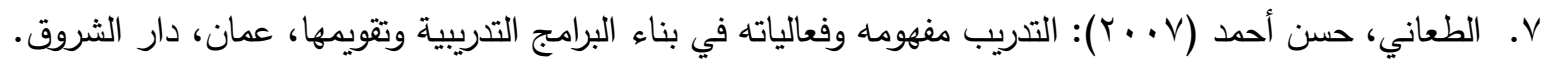

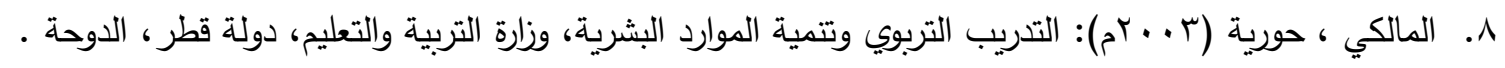

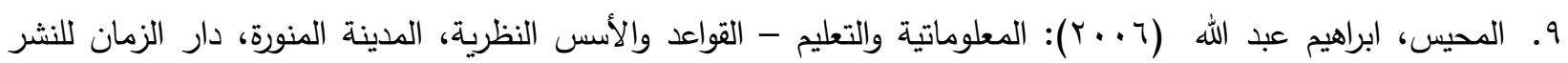

والتوزيع.

• (. المنظمة العربية للتربية والثقافة والعلوم (9V9 (م)): تقرير استراتيجية تطوير التربية العربية. الـبشارة، جبرائيل (ع^91 (م): تدريب المعلمين أثناء الخدمة (مفهومه، أهدافه، اتجاهاته، المستقبلية)، المؤتمر الأول حول

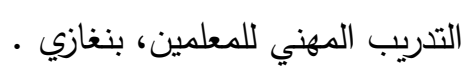

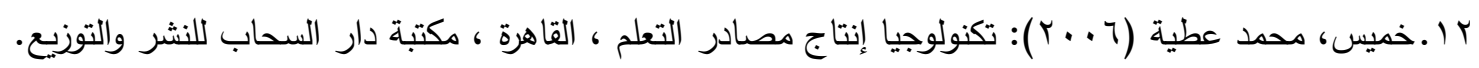

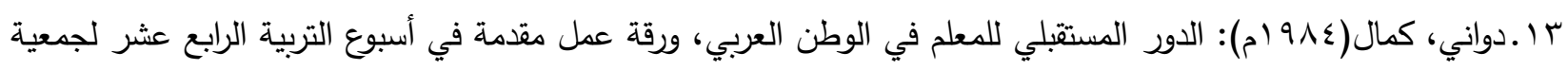
المعلمين الكويتية، الكويت.

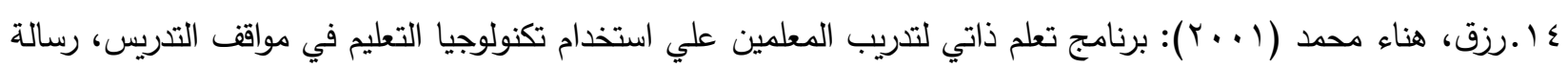

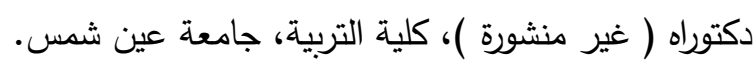

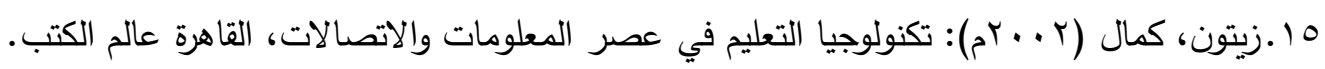

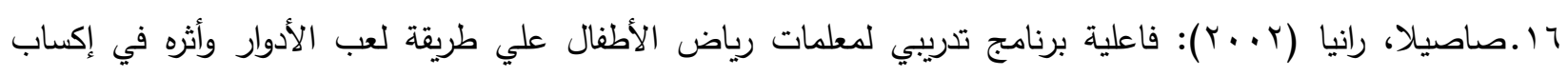

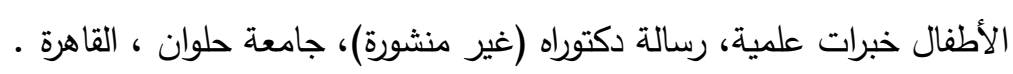

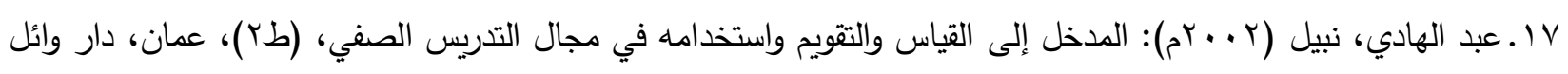
للنشر

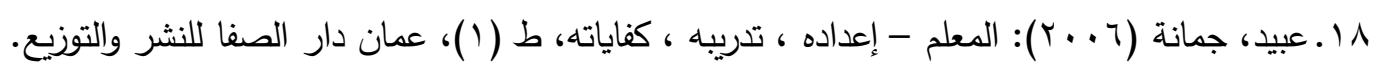

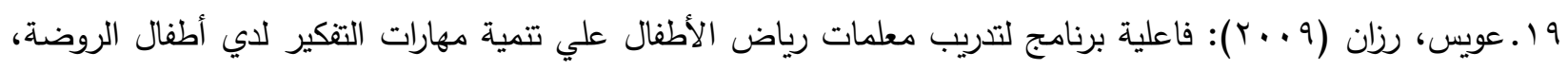

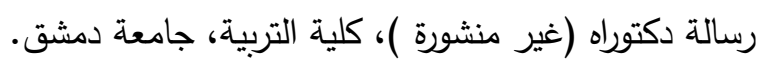




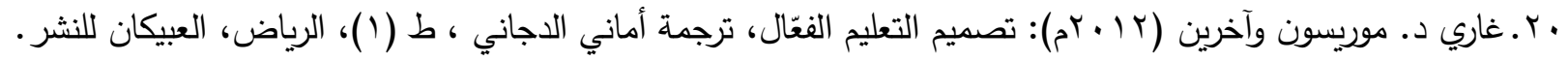

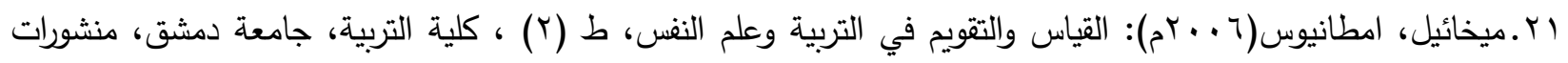
جامعة دمشق. r r r. بكيبيديا، الموسوعة الحرة، ولاية الجزيرة. ثانياً: المراجع الأجنبية:

[1] Austin,E.L (2003) : Standards for teacher competence in kindergarten, http://www.allacademic.com/meta/p106668_index.htm . Education Assessment of students “ Paper presented at the annual meeting of the American Sociological Association.

[2] Kemp J.E.(1985): The Instructional Design Process . New York.

[3] Selven ,Eileen (2003), Basic Performance competency and Measure Teachers Doing it in Kindergarten, Recourses for Education ,ERIC,ED(47686) 


\title{
Building a Training Program (Proposed) to Develop the Educational Competencies of Pre-School Teachers During the Service in the State of Al- Gazira - Sudan
}

\author{
Dr. Khalid Mahgoub Abd Alla Mahmoud \\ Assistant Professor of Curriculum and Teaching Methods- Department of Education \\ Faculty of Education Alhasahisa - University of Gazira - Sudan \\ khalid.mahgoub565@gmail.com
}

\begin{abstract}
:
The objective of the research aimed to construct a training program (proposed) for the development of the educational competencies of pre-school teachers during the service in the state of Gazira. The search population was 6,376. The researcher used the inductive method in monitoring the training needs of the teachers and descriptive approach in describing the training program. The training program was structured in the following steps:

- Determining the training needs of pre-school teachers in the state of Gazira through the survey conducted by the researcher with the participation of the Pre-school education Department technical guidance and the education management sections in Gazira state.

- Setting the objectives of the training program in light of the philosophy and objectives of preschool education in Sudan.

- Selection of content and training activities that would achieve the needed development of the educational competencies of the trainees.

- Selection of the implementation, evaluation and training methods and techniques of the program that facilitates the training.

- Design the training program and choose the appropriate training model that suits the objectives of the program. The researcher adopted the comprehensive model of the design of education and training (J. Kemp: 1985) for its suitability to the nature of the training program.

- Preparation for the implementation of the program, where the requirements for the implementation of the human and material program and the development of an implementation plan including the timetable for implementation of the program.

- Implementation of the training program according to the plan.

- Evaluation of the training program to determine the extent of meeting the proposed objectives.

At the end of the research, the researcher presented several recommendations and proposals for future research.
\end{abstract}

Keywords: training program for pre-school teachers. 